\title{
Human Appendix B Cells Naturally Express Receptors for and Respond to Interleukin 6 with Selective IgA1 and IgA2 Synthesis
}

\author{
Kohtaro Fujihashi, " Jerry R. McGhee, ${ }^{\star *}$ Cummins Lue, ${ }^{*}$ Kenneth W. Beagley, "Tetsuya Taga," \\ Toshio Hirano," Tadamitsu Kishimoto," Jiri Mestecky, \\ Departments of ${ }^{*}$ Oral Biology, ${ }^{\ddagger}$ Microbiology, and ${ }^{\S}$ Medicine, University of Alabama at Birmingham, UAB Station, Birmingham, \\ Alabama 35294; and "Division of Immunology, Institute for Molecular and Cellular Biology, \\ Osaka University, Yamadaoka, Suita, Osaka 565, Japan
}

\begin{abstract}
Past studies have shown that freshly isolated human B cells from peripheral blood and tonsils do not express IL-6 receptors (IL-6R); however, mitogen or antigen activation of these B cells induces IL-6R and responsiveness to IL-6. In this study, we have shown that a high proportion of $B$ cells enzymatically dissociated from human appendix, a gut-associated lymphoreticular tissue (GALT), expresses the IL-6R, and that recombinant human IL-6 induces significant increases in the number of Ig-producing cells. The recombinant human IL-6-induced increase in Ig-producing cells is restricted to the IgA isotype. Further, IgA2 is the major subclass; however, significant numbers of IgA1 producing cells are also seen. In contrast, human tonsillar and peripheral blood B cells express low levels of IL6R, and exogenous IL-6 does not increase numbers of Ig-producing cells. When PBMC or tonsillar cells are stimulated with PWM, the former display an equal distribution of IgA1 and IgA2 secreting cells, while tonsillar B cells are mainly of the IgA1 subclass. The distribution of surface $\mathrm{Ig}$-positive $\left(\mathrm{sIg}^{+}\right) \mathrm{B}$ cells in the appendix $B$ cell population is $\operatorname{sIgA}^{+}>$sIgG $^{+}$ $>$ sIgM $^{+}$, and the sIgA ${ }^{+}$B cells express higher levels of IL-6R when compared with sIgG $^{+}$or sIgM $^{+} B$ cells. These studies show that human appendix contains $B$ cell subsets that constitutively express IL-6R, and that a high proportion of these cells are committed to the IgA isotype. Furthermore, higher numbers of IL-6 responsive IgA2 B cells are present in the human appendix as compared to tonsils or PBMC. (J. Clin. Invest. 1991. 88:248-252.) Key words: appendix • gut-associated lymphoreticular tissues - IgA subclass spot-forming cells • IL-6 - IL-6 receptor
\end{abstract}

\section{Introduction}

IL-6 was originally described as a T cell-derived cytokine that induced the terminal differentiation of B cells (1). It also acts as a growth factor for plasmacytomas and myelomas (2-4), and like other cytokines stimulates multiple cell types, including hematopoietic stem cells, nerve cells, hepatocytes, and both $T$ and B lymphocytes (1, 4-6). A variety of cell types, including $T$

Address correspondence to Dr. Hiroshi Kiyono, Department of Oral Biology, BHS 392, The University of Alabama at Birmingham Medical Center, UAB Station, Birmingham, AL 35294.

Received for publication 25 June 1990 and in revised form 31 January 1991.

J. Clin. Invest.

(c) The American Society for Clinical Investigation, Inc.

0021-9738/91/07/0248/05 \$2.00

Volume 88, July 1991, 248-252 lymphocytes, macrophages, fibroblasts, endothelial and epithelial cells produce this interleukin when stimulated with virus or bacterial products, cytokines (e.g., IL-1 and tumor necrosis factor $\alpha$ ), and lectins $(4,6-8)$. For cells of the B lineage, IL-6 is mainly involved in maturation of activated B cells $(9,10)$ and enhances Ig secretion in EBV-transformed B cells (11). IL-6 can also augment IgM, IgG, and IgA synthesis in cultures of PWM-induced B cell blasts (12) and its effect can be ablated by addition of anti-IL-6 antibody (12). IL-6 receptor (IL-6R) ${ }^{1}$ is known to be expressed on PWM-induced B cell blasts but not on unstimulated B cells (13). IL-6 induces Ig secretion in Staphylococcus aureus Cowan I-activated B cells $(1,14)$, but its effect in this culture system depends upon the presence of IL-2 (15). Although these studies indicate the importance of IL- 6 in B cell maturation, little information is available on the importance of this cytokine in regulation of human $\operatorname{IgA}$, including $\operatorname{IgA} 1$ and IgA2 subclass responses. Our previous studies have shown that murine IL-6 is of central importance for the induction of committed, surface IgA-positive $\left(\operatorname{sIgA}^{+}\right)$B cells to become IgA-secreting cells $(16,17)$. In those studies, $B$ cells were obtained from murine Peyer's patches (PP), an IgA-inductive site that is enriched in $\operatorname{sIg} A^{+}$cells, and IL-6 was shown to induce $\operatorname{sIg} A^{+} B$ cell blasts to terminally differentiate into IgA-producing plasma cells $(16,17)$.

In this study we have assessed B cells from human appendix, a gut-associated lymphoreticular tissue (GALT), for their expression of IL-6R and for their responsiveness to recombinant human IL-6 (rhIL-6). Since GALT is considered to be an IgA inductive site, we have evaluated the effects of rhIL- 6 on both IgA1 and IgA2 subclass responses at the single cell level, without mitogen stimulation.

\section{Methods}

Lymphocyte preparations. The PBMC were obtained from healthy donors and isolated by centrifugation over a Ficoll-Hypaque density gradient. Normal appendix tissues were obtained during gall bladder surgery or autopsy. The tonsils were obtained from patients undergoing tonsillectomy. These tissues were obtained through the Tissue Procurement Core Facility in the Comprehensive Cancer Center at University of Alabama at Birmingham. Appendix and tonsillar tissues were washed with incomplete RPMI 1640 (containing sodium pyruvate, Lglutamine, nonessential amino acids, Hepes buffer, gentamycin, penicillin, and streptomycin) and the muscular fibrous layer removed under sterile conditions. Both appendix and tonsillar tissues were cut into $0.5-1.0-\mathrm{cm}$ segments and the cells were dissociated by use of the

1. Abbreviations used in this paper: ELISPOT, enzyme-linked immunospot; GALT, gut-associated lymphoreticular tissue; IL-6R, IL-6 receptor; PP, Peyer's patches; rhIL-6, recombinant human IL-6; SFC, spot-forming cells; sIgA ${ }^{+}$, surface IgA positive. 
neutral protease Dispase ${ }^{\oplus}$ as previously described (18). Briefly, Joklik's MEM containing $1.5 \mathrm{mg} / \mathrm{ml}$ Dispase ${ }^{\oplus}, \mathrm{pH} 7.4$, was added to petri dishes with appendix tissues. After $30 \mathrm{~min}$ incubation at $37^{\circ} \mathrm{C}$ with continuous stirring, the cell suspension was harvested and washed extensively with incomplete RPMI 1640 to remove residual enzyme. Cells were then resuspended in incomplete RPMI 1640 containing $2 \%$ FCS. This procedure was repeated at least five times, the cells from each fraction were pooled, and the mononuclear cells isolated by Ficoll-Hypaque density gradient centrifugation. After extensive washing, cells were resuspended in complete RPMI 1640 (incomplete medium containing $10 \% \mathrm{FCS}$ ) and incubated at $37^{\circ} \mathrm{C}$ in $5 \% \mathrm{CO}_{2}$ for $12-18 \mathrm{~h}$. This procedure allowed the reexpression of surface molecules on lymphocytes and removed adherent cells, including monocytes and macrophages. The cell viability of PBMC, appendix and tonsillar lymphocytes was determined by trypan blue dye exclusion, and was $>98 \%$.

Recombinant human IL-6, polyclonal anti-hIL-6, and monoclonal anti-IL-6R antibodies. rhIL-6 was obtained from IL-6-specific cDNA expressed in Escherichia coli (19). Briefly, the plasmid pTBCDF-12 containing the $E$. coli trp promotor was constructed to generate a pT911 fusion protein. Biologically active rhIL- 6 was then obtained by the digestion of the translated fusion protein with kallikrein and aminopeptidase $P$. This recombinant protein was further purified by reversed-phase HPLC. The purity of rhIL-6 was $>95 \%$ and its biological activity was determined by induction of proliferation with the IL-6-dependent MOPC 104E KD 83 (KD 90) cell line (see below) and terminal differentiation was assessed with murine PP B cells (16). Polyclonal anti-human IL- 6 antibody was obtained by the immunization of a goat with rhIL-6. This antibody neutralized rhIL-6 at a dilution of up to $10^{-5}$; however, this antibody did not neutralize human IL-2, IL-4, or IL-5 (16). Monoclonal anti-IL-6R (MT 18) antibody was generated from a hybridoma derived from spleen cells of C57BL/6 mice immunized with the human IL-6R cDNA transfected CTIL6R cells (13). The MT18 MAb recognized IL-6R on both T and B cells. Further, this MAb was not inhibited by IL-6 in its binding to the IL-6R (13).

In vitro cultures. The B cells from appendix, tonsils, and PBMC were obtained after removal of $T$ cells by rosetting with 2-Aminoethylisothiouroniumbromide (AET)-sheep erythrocyte (SRBC) for two to three cycles. AET-SRBC rosette-negative cells were used as the B cellenriched fraction. Flow cytometry analysis using FITC-Leu $12 \mathrm{MAb}$ showed that this fraction contained $>95 \%$ B cells. Appendix and tonsillar B cells were cultured $\left(1 \times 10^{6} \mathrm{cells} / \mathrm{ml}\right)$ in complete medium for 7 d either in the presence or absence of $20 \mathrm{U} / \mathrm{ml}$ of rhIL-6. In some experiments, cultures were harvested after $3 \mathrm{~d}$ of incubation. Nonadherent cells were harvested, washed twice with medium, and tested in the enzyme-linked immunospot (ELISPOT) assay as described below. In other experiments, PBMC and tonsillar mononuclear cells were cultured $\left(1 \times 10^{6} \mathrm{cells} / \mathrm{ml}\right)$ with PWM (1:200 dilution) for $48 \mathrm{~h}$ at $37^{\circ} \mathrm{C}$ in $5 \% \mathrm{CO}_{2}$. Nonadherent cells were removed, washed, and cultured in the presence or absence of $20 \mathrm{U} / \mathrm{ml}$ of rhIL-6. The cells were incubated for an additional 5-d period and assessed for single cell Ig production by the ELISPOT assay.

Enumeration of spot-forming cells (SFC) by ELISPOT. To determine the numbers of IgM, IgG, and IgA, including IgA 1- and IgA2-producing cells, the ELISPOT assay was employed as previously described (18). Briefly, 96-well plates with a nitrocellulose base (Millititer HA; Millipore Corp., Bedford, MA) were coated with affinity-purified goat $\mathrm{F}\left(\mathrm{ab}^{\prime}\right)_{2}$ anti-human IgM (Pel-Freez Biologicals, Rogers, AR), anti-human IgG (Jackson Immunoresearch Laboratories, Inc., West Grove, PA) or anti-human IgA (Pel-Freez). After blocking with RPMI 1640 containing 5\% FCS, cells were incubated on coated plates for $4 \mathrm{~h}$ at $37^{\circ} \mathrm{C}$ in a humidified atmosphere of $5 \% \mathrm{CO}_{2}$ in air. The plates were washed with PBS and PBS-Tween $20(0.05 \%)$, and further incubated overnight at $4^{\circ} \mathrm{C}$ with biotinylated goat $\mathrm{F}\left(\mathrm{ab}^{\prime}\right)_{2}$ anti-human IgM, antihuman IgG, or anti-human IgA (Tago Inc., Burlingame, CA). Plates were then washed and incubated with avidin-peroxidase $(1 \mu \mathrm{g} / \mathrm{ml})$ for 2 $h$ at $25^{\circ} \mathrm{C}$. Spots representing Ig-secreting cells of the respective isotype were visualized by development with the substrate 3-amino-9-ethylcarbazole in $0.1 \mathrm{M}$ citrate, $\mathrm{pH} 5.0$.
To determine the frequency of IgA1- and IgA2-producing cells, nitrocellulose plates were coated with anti-human $\alpha 1$ or anti-human $\alpha 2$ MAbs (kindly provided by Dr. J. Radl [TNO, Institute of Experimental Gerontology]). Cells were added to the wells and incubated in the same manner as described above (18). IgA subclass-specific SFC were enumerated by the addition of biotinylated goat $F\left(a b^{\prime}\right)_{2}$ anti-human IgA (Tago) followed by avidin-peroxidase as indicated above. Spots were enumerated with the aid of a dissecting microscope.

$I L-6$ receptor expression. Purified B cells from the appendix or from PWM-triggered PBMC cultures were reacted with biotinylated monoclonal anti-human IL-6R (MT-18) (13) for $30 \mathrm{~min}$ at $4^{\circ} \mathrm{C}$. After washing twice with PBS containing $2 \%$ FCS and $0.01 \%$ sodium azide, the cells were stained with avidin-phycoerythrin (PE). The cells were subjected to flow cytometry analysis using a FACStar (Becton Dickinson \& Co., Sunnyvale, CA). In other experiments, purified appendix B cells were incubated with FITC-conjugated anti-human $\mu$, or $-\gamma$ or $-\alpha$ antibodies (Southern Biotechnology Associates, Birmingham, AL). The cells were costained for expression of IL-6R as described above and two-color analysis performed.

\section{Results}

rhIL-6 preferentially augments in vitro IgA subclass production by appendix $B$ cells. Since our past work has shown that IL-6 induced significant IgA synthesis in mouse PP B cell cultures (16), it was important to determine if human GALT B cells could also be induced by this cytokine to secrete Ig. When purified appendix B cells were incubated with rhIL-6 for $7 \mathrm{~d}$, significant increases in IgA SFC were found (Fig. 1). In this regard, a smaller increase in numbers of IgA producing cells $(10-15 \%)$ was already noted after $3 \mathrm{~d}$ in culture, while $300-$ $400 \%$ increases in IgA SFC were seen after $7 \mathrm{~d}$ in culture (Fig. 2). The SFC responses were due to de novo synthesis of IgA, since addition of cycloheximide to cultures inhibited SFC responses by $85-90 \%$. Smaller increases in the number of SFC were seen for IgM and IgG isotypes. In contrast, addition of the

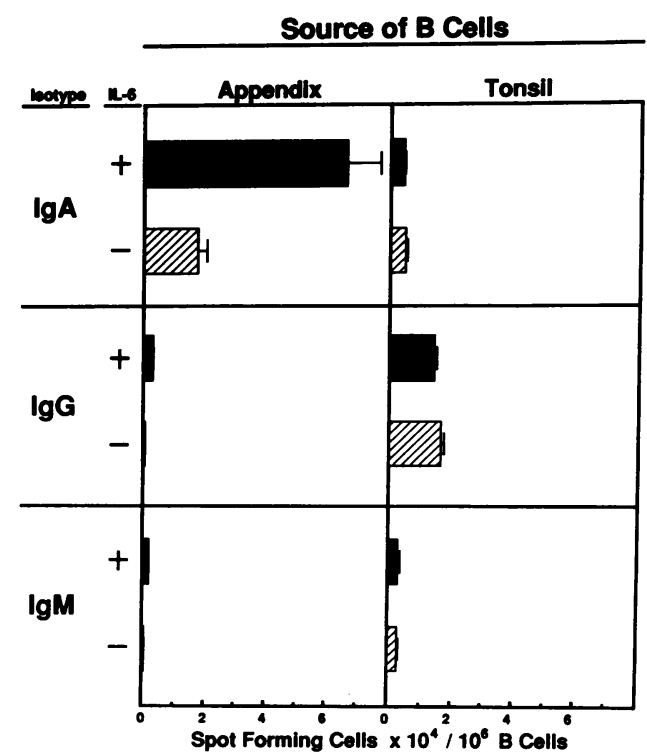

Figure 1. Effect of IL-6 on B cells isolated from human GALT. Purified $B$ cells from appendix and tonsils $\left(1 \times 10^{6} / \mathrm{ml}\right)$ were cultured in the presence (a) or absence (घ) of rhIL-6 for $7 \mathrm{~d}$. Nonadherent cells were harvested and tested in the ELISPOT assay to enumerate IgM-, IgG-, and IgA-SFC. Values are expressed as mean \pm SE of four separate experiments. 


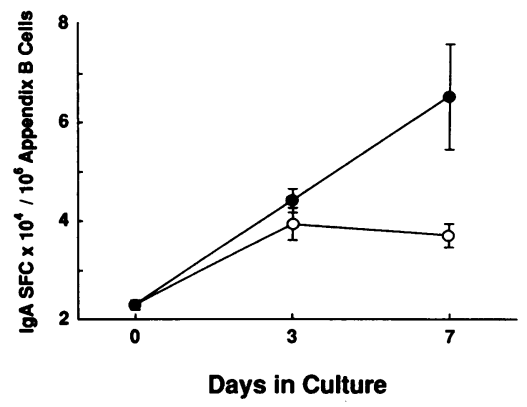

Figure 2. Kinetics of IL-6 effects on appendix B cells. Purified B cells from appendix (1 $\times 10^{6} / \mathrm{ml}$ ) were incubated in the presence $(\bullet-\bullet)$ or absence (O- 0 ) of rhIL-6 for 3 and $7 \mathrm{~d}$. Nonadherent cells were harvested and subjected to IgA-specific ELISPOT assay. Values are expressed as mean \pm SE of two separate experiments.

same amount of rhIL-6 to tonsillar B cell cultures did not enhance the numbers of IgM, IgG, and IgA SFC (Fig. 1) unless the cells were prestimulated with PWM (data not shown), confirming results from a previous study (12). This represents the first study that shows that IL-6 can induce Ig synthesis in freshly isolated human B cell cultures without mitogen or antigen costimulation. Further, the effect was largely confined to the IgA isotype.

Since human IgA occurs as two subclasses, we next assessed the effect of rhIL-6 for induction of IgA1 and IgA2 synthesis. Of interest was the finding that appendix B cells without stimulation exhibited more spontaneous IgA2 secreting cells than IgA1 (Table I). In contrast, freshly isolated tonsillar B cells contained lower numbers of IgA producing cells when compared with appendix B cells, and the majority of IgA producing cells were of the IgA1 subclass (Table I). Addition of rhIL-6 resulted in three-to fourfold increases in both IgA1 and IgA2 SFC responses in appendix B cells, while no IL-6 effect was seen in tonsillar B cells. The IgA2 response represented $\sim 60$ $70 \%$ of the total IgA response seen with appendix B cells (Table I). The increase in IgA1 and IgA2 SFC was indeed due to IL-6, since addition of anti-IL-6 antibodies to appendix B cell cultures completely abrogated the effect of that cytokine. These results show that rhIL-6 induces GALT B cells to terminally differentiate into IgA1- or IgA2-secreting cells.

Table I. Recombinant Human IL-6 Augments the Number of IgA1- and IgA2-Producing Cells in Appendix B Cell Cultures*

\begin{tabular}{|c|c|c|c|c|}
\hline \multirow[b]{3}{*}{ IL-6 Added } & \multicolumn{4}{|c|}{ Source of $B$ cells and number of $\operatorname{IgA} 1$ and $\operatorname{IgA} 2 \mathrm{SFC}\left(/ 10^{6}\right.$ cells) } \\
\hline & \multicolumn{2}{|c|}{ Appendix } & \multicolumn{2}{|c|}{ Tonsils } \\
\hline & IgA1 & IgA2 & IgAI & IgA2 \\
\hline+ & $33,571 \pm 2,320$ & $46,485 \pm 4,566$ & $4,131 \pm 135$ & $112 \pm 31$ \\
\hline- & $10,444 \pm 1,597$ & $15,225 \pm 2,363$ & $4,552 \pm 756$ & $100 \pm 35$ \\
\hline
\end{tabular}

Freshly isolated $\quad 8,640 \pm 404 \quad 20,900 \pm 519 \quad 4,187 \pm 344 \quad 165 \pm 15$

* Purified appendix and tonsillar B cells $\left(1 \times 10^{6} / \mathrm{ml}\right)$ were incubated for $7 \mathrm{~d}$ with recombinant human IL-6 $(20 \mathrm{U} / \mathrm{ml})$. Aliquots of purified B cells were immediately subjected to IgA subclass specific ELISPOT assay and indicated as freshly isolated. Control cultures were incubated without any stimulants. At the end of culture, cell viability was determined by trypan blue dye exclusion and IgA1 and IgA2 SFC were enumerated by ELISPOT assay. Numbers are expressed as IgA1or IgA2-specific SFC \pm SE from five separate experiments.

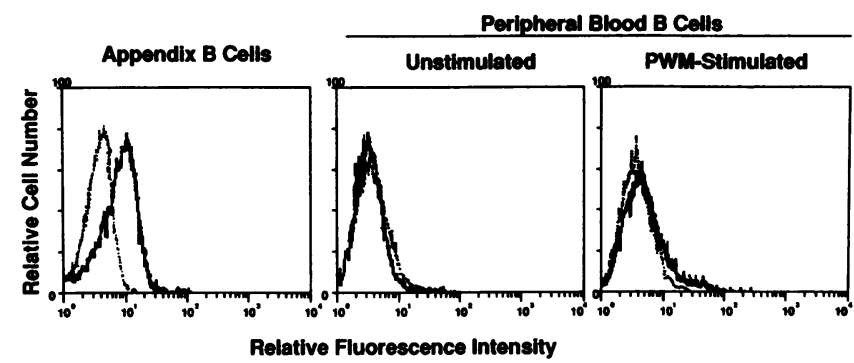

Figure 3. Analysis of IL-6R expression on appendix B cells. Purified B cells from appendix were first reacted with biotinylated MAb anti-IL6R (MT-18) followed by avidin-PE (solid line). As controls, B cells were isolated from PWM-stimulated and nonstimulated PBMC, and stained for the expression of IL-6R. Samples were then analyzed by flow cytometry. The dotted line indicates cells which were incubated with avidin-PE only. This profile was essentially the same as cells only.

Correlation of $I L-6 R$ expression with appendix $\operatorname{sIg} A^{+} B$ cells. The finding that appendix B cells are responsive to rhIL-6 would suggest that GALT B cell subsets constitutively express IL-6R. To test this hypothesis, freshly isolated appendix B cells were reacted with MAb anti-IL-6R (MT-18). A high expression of IL-6R was seen on these cells (Fig. 3). On the other hand, B cells isolated from PBMC (Fig. 3), spleen, or tonsils (data not shown) did not express IL-6R unless they were stimulated with PWM. The intensity of IL-6R expression on appendix B cells was stronger than on PWM-stimulated peripheral blood B cells. Thus, the appendix represents the only human lymphoid tissue studied to date that contains B cells that endogenously express IL-6R.

We next examined the expression of IL-6R on appendix B cell subsets according to their isotype expression of membrane immunoglobulin. Two-color flow cytometry analysis revealed that $\operatorname{sIg} \mathrm{A}^{+} \mathrm{B}$ cells expressed higher levels of IL-6R than were seen with sIgM $^{+}$or $\mathrm{sIgG}^{+}$B cells (Fig. 4). This would explain
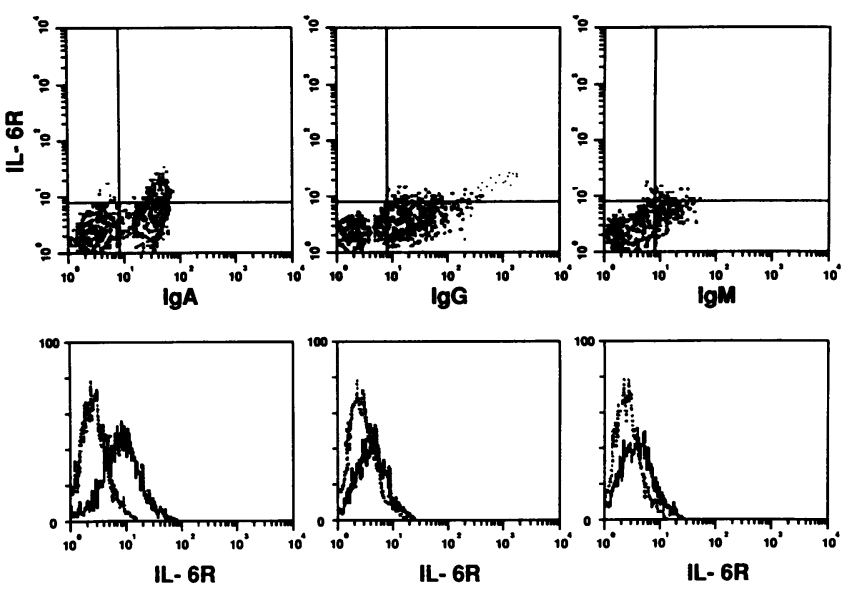

Figure 4. Comparison of IL-6R expression on different subsets of appendix B cells which bear surface IgA, IgG, or IgM. Purified B cells from appendix were first incubated with FITC-anti-human IgM, anti-human IgG, or anti-human IgA, followed by staining with biotinylated anti-IL-6R and avidin-PE. Two color analysis was then performed by flow cytometry (upper panel). Vertical and horizontal gating lines described in the profiles were set according to the profile of unstained cells and cells incubated with avidin-PE only. In the lower panel, the relative intensity of IL-6R expression in $\mathrm{sIgA} \mathrm{A}^{+}, \mathrm{sIgG}^{+}$, or sIgM $^{+}$B cell subsets was compared by histogram display. 
the tendency of appendix B cells to differentiate into IgA-secreting cells in the presence of rhIL-6. Further, relatively high frequencies of $\operatorname{sig} \mathrm{A}^{+} \mathrm{B}$ cells, e.g., $\sim 51 \%$, occurred in the appendix, while $<2 \%$ of PBMC or spleen $B$ cells expressed this membrane isotype.

\section{Discussion}

In this study, purified B cells from human appendix were used to determine the role of IL-6 in regulation of human IgA synthesis. This population had the advantage of containing a high frequency of $\operatorname{sIg} \mathrm{A}^{+}$B cells (20). Moreover, the appendix has been shown to exhibit features of GALT, and this includes a dome region covered by a unique epithelium containing follicle-associated or microfold cells, that function in the uptake of gut antigens for the induction of mucosal immune responses (21). Thus, the appendix has anatomical and functional characteristics in common with PP which have been well characterized in mice and shown to be major IgA inductive sites $(17,22)$. The PP have been shown to contain T cell subsets that induce B cells to switch from surface IgM to surface IgA expression, and other subsets which selectively supported IgA responses (17, 22). In this respect, cloned $T$ cells have also been derived from human appendix which induced both $\operatorname{sIgM}^{+} \rightarrow \operatorname{sIgA}^{+}$switches and IgA synthesis (23). Further, interleukins, most notably IL5 and IL-6, induced $\operatorname{IgA}{ }^{+}$PP B cells to secrete $\operatorname{IgA}(16,17)$. It is difficult to isolate human PP; therefore, studies of $T$ cell and cytokine regulation of IgA responses have been largely limited to lymphoid tissues other than GALT.

The finding that human appendix B cells responded to rhIL-6 without mitogen costimulation is a novel finding. Previous work had indicated that human B cells from peripheral blood, spleen, and tonsils required activation for expression of IL-6R and for induction of Ig synthesis by this cytokine (11-15). In contrast, our results have shown that B cells freshly isolated from the appendix express high levels of IL-6R. Further, the highest intensity of IL-6R was noted on sIgA ${ }^{+} B$ cells. This most likely explains the predominant IgA SFC responses seen after cultivation with rhIL-6. These results clearly favor the notion that the appendix is an IgA inductive site, and in this regard resembles the murine PP (22). Collectively, our studies suggest that murine PP and human appendix are enriched for sIgA ${ }^{+} B$ cells, and that these subsets are responsive to IL-5 and IL-6 (mouse), and to IL-6 (human), which induce terminal differentiation into IgA plasma cells.

One should point out that $\sim 7-10 \%$ of appendix B cells were induced to differentiate into IgA secreting plasma cells. Our study further showed that $\sim 50 \%$ of appendix B cells are sIgA $^{+}$(Fig. 4). Taken together, one could suggest that a relatively small percentage of $\operatorname{sIg} A^{+} B$ cells in human GALT respond to IL-6 and differentiate into plasma cells. This study, however, does not define the nature of this subset of $\operatorname{sIg}{ }^{+} B$ cells that are responsive for IL-6. In this regard, it will be necessary to further separate $\operatorname{sIg} \mathrm{A}^{+} \mathrm{B}$ cells into subsets according to the coexpression of other surface Igs (e.g., sIgM $^{+}, \operatorname{sIgA}^{+} B$ cells vs. $\operatorname{sIgM}^{-}, \operatorname{sIgA}^{+} B$ cells) and to their intensity of IL-6R expression (e.g., high vs. low) as well as their possible occurrence in germinal centers. Studies along these lines will be required to elucidate the precise nature of $\operatorname{sIgA}^{+} B$ cells in GALT that are directly responsive to IL- 6 and subsequently differentiate into plasma cells. It is not yet clear why GALT sIgA ${ }^{+}$B cells express more IL-6R when compared with sIgM $^{+}$and sIgG $^{+}$B cells; however, this may explain why IgM and IgG are produced less in the mucosal immune system. This cannot be explained by more frequent sIgM $\rightarrow$ sIgA B cell switches, since the appendix contains significant numbers of $\operatorname{sIgG}^{+}$(this study) and IgG-producing cells (24). A more plausible explanation would be that $\mathrm{sIgM}^{+}$and $\mathrm{sIgG}{ }^{+}$B cells expressed IL-2R and required this cytokine for full expression of IL-6R. In this regard, it was recently shown that IL-2 was required, together with $S$. aureus Cowan I mitogen, for human B cells to be responsive to IL-6 for subsequent Ig synthesis (15). We are currently analyzing the expression of IL-2R on appendix $B$ cell subsets, and the requirement for IL-2 for induction of IL-6R on $\operatorname{sIgM}^{+}$and $\operatorname{sIgG}^{+}$B cells.

When the frequency of IgA1 and IgA2 cells was compared between appendix and tonsils, two distinct patterns of IgAl and IgA2 subclass production were noted. Appendix B cells were characterized as an enriched source of IgA2 cells, while tonsils contained predominantly IgA1 producing cells. Our recent studies have shown that approximately equal numbers of sIgA ${ }^{+} B$ cells in both appendix and tonsil coexpress IL-2R and transferrin receptors (Fujihashi, K., et al., manuscript in preparation). However, an important difference was noted between $\operatorname{sIgA}^{+} \mathrm{B}$ cells in these two tissues and included IL-6R expression and cell size. In this regard, the appendix $\operatorname{sig} A^{+} B$ cells were large blasts and expressed IL-6R (data not shown). Furthermore, B cells isolated from appendix responded well to IL-6 without any costimulation, while tonsillar B cells did not. These findings suggested that although both appendix and tonsils are organized secondary lymphoid tissues, residing IgAcommitted B cells are distinct in terms of their role in the induction of $\operatorname{IgA} 1$ and $\operatorname{IgA} 2$ responses in humans.

The finding that higher frequencies of IgA2 subclass SFC were induced by rhIL-6 in appendix B cell cultures also merits comment. It has been well established that serum IgA is largely derived from the bone marrow and consists mainly of monomers of the IgA1 subclass (22). On the other hand, $\operatorname{IgA} 2$ is found in higher proportions in external secretions (22), and IgA2 plasma cells are more frequent in lamina propria regions of the gastrointestinal tract $(24,25)$. Our studies would suggest that the appendix may represent a major source of IgA2-committed B cells destined for homing to those mucosal tissues. We are currently assessing the molecular size of $\operatorname{IgA} 1$ and $\operatorname{IgA} 2$ produced by IL-6-stimulated appendix B cells.

In summary, we have shown that freshly isolated human appendix B cells express high levels of IL-6R and respond to rhIL-6 with significant increases (three-to fivefold) in the number of IgA-secreting cells. Furthermore, $\operatorname{sIgA}^{+} \mathrm{B}$ cells from appendix express more IL-6R than is seen with $\operatorname{sIgM}^{+}$or $\operatorname{sIgG}^{+}$B cells. When IgA subclass responses were measured, rhIL-6 induced both IgA1 and IgA2 SFC responses; however, $60-70 \%$ of the total response was represented by the $\operatorname{IgA} 2$ subclass. Our studies suggest that the human appendix is an enriched source for $\operatorname{sIgA}{ }^{+} B$ cells that are responsive to IL- 6 for the terminal differentiation into IgA plasma cells.

\section{Acknowledgments}

We thank Ms. M. L. McGhee for excellent technical assistance. We also thank Ms. D. Clisby for typing this manuscript.

This work was supported by National Institutes of Health grants AI-18958, AI-21032, AI-19674, DE-04217, AI-28147, DE-08228, DE- 
08182, AI-18745, AI-30366, and AI-10854. H. Kiyono is the recipient of Research Career Development Award DE 00237.

\section{References}

1. Hirano, T., T. Taga, N. Nakano, K. Yasukawa, S. Kashiwamura, K. Shimizu, K. Nakajima, K. H. Pyun, and T. Kishimoto. 1985. Purification to homogeneity and characterization of human B-cell differentiation factor (BCDF or BSFp2). Proc. Natl. Acad. Sci. USA. 82:5490-5494.

2. Zilberstein, A., R. Ruggieri, J. H. Korn, and M. Revel. 1986. Structure and expression of cDNA and genes for human interferon-beta-2, a distinct species inducible by growth-stimulatory cytokines. EMBO (Eur. Mol. Biol. Organ.) J. 5:2529-2537.

3. Haegeman, G., J. Content, G. Volckaer, R. Derynck, J. Tavernier, and W. Fiers. 1986. Structural analysis of the sequence coding for an inducible 26-kDa protein in human fibroblasts. Eur. J. Biochem. 159:625-632.

4. Van Damme, J., G. Opdenakker, R. J. Simpson, M. R. Rubira, S. Cayphas, A. Vink, A. Billiau, and J. Van Snick. 1987. Identification of the human 26-kD protein, interferon $\beta 2$ (IFN- $\beta 2$ ), as a B cell hybridoma/plasmacytoma growth factor induced by interleukin 1 and tumor necrosis factor. J. Exp. Med. 165:914919.

5. Van Damme, J., J. Van Beeumen, B. Decock, J. Van Snick, M. De Ley, and A. Billiau. 1988. Separation and comparison of two monokines with lymphocyteactivating factor activity: IL-1 $\beta$ and hybridoma growth factor (HGF). Identification of leukocyte-derived HGF as IL-6. J. Immunol. 140:1534-1541.

6. Jirik, F. R., T. J. Podor, T. Hirano, T. Kishimoto, D. J. Lockutoff, D. A Carson, and M. Lotz. 1989. Bacterial lipopolysaccharide and inflammatory mediators augment IL-6 secretion by human endothelial cells. J. Immunol. 142:144 147.

7. Sehgal, P. B., D. C. Helfgott, U. Santhanam, S. B. Tatter, R. H. Clarick, J. Ghrayeb, and L. T. May. 1988. Regulation of the acute phase and immune responses in viral disease: enhanced expression of the $\beta 2$-interferon/hepatocytestimulating factor/interleukin 6 gene in virus-infected fibroblasts. J. Exp. Med. 167:1951-1956.

8. Kohase, M., D. Henriksen-DeStefano, L. T. May, J. Vilcek, and P. B. Sehgal. 1986. Induction of $\beta 2$-interferon by tumor necrosis factor: a homeostatic mechanism in the control of cell proliferation. Cell. 45:659-666.

9. Kishimoto, T., and T. Hirano. 1988. Molecular regulation of B lymphocyte response. Annu. Rev. Immunol. 6:485-512.

10. Kishimoto, T. 1989. Review article. The biology of interleukin-6. Blood. 74:1-10.

11. Kikutani, H., T. Taga, S. Akira, H. Kishi, Y. Miki, O. Saiki, Y. Yamaura and T. Kishimoto. 1985. Effect of B cell differentiation factor (BCDF) on biosynthesis and secretion of immunoglobulin molecules in human B cell lines. J. Immunol. 134:990-995.
12. Muraguchi, A., T. Hirano, B. Tang, T. Matsuda, Y. Horii, K. Nakajima, and T. Kishimoto. 1988. The essential role of B cell stimulatory factor 2 (BSF-2/ IL-6) for the terminal differentiation of B cells. J. Exp. Med. 167:332-344.

13. Hirata, Y., T. Tetsuya, M. Hibi, N. Nakano, T. Hirano, and T. Kishimoto. 1989. Characterization of IL-6 receptor expression by monoclonal and polyclonal antibodies. J. Immunol. 143:2900-2906.

14. Nakagawa, T., N. Nakagawa, H. Goldstein, D. J. Volkman, and A. S. Fauci. 1986. Demonstration that human B cells respond differently to interleukin 2 and B cell differentiation factor based on their stages of maturation. $\mathrm{J}$. Immunol. 137:3175-3182.

15. Splawski, J. B., L. M. McAnally, and P. E. Lipsky. 1990. IL-2 dependence of the promotion of human B cell differentiation by IL-6 (BSF-2). J. Immunol. 144:562-569.

16. Beagley, K. W., J. H. Eldridge, F. Lee, H. Kiyono, M. P. Everson, W. J. Koopman, T. Hirano, T. Kishimoto, and J. R. McGhee. 1989. Interleukins and IgA synthesis. Human and murine interleukin 6 induce high rate IgA secretion in IgA-committed B cells. J. Exp. Med. 169:2133-2148.

17. McGhee, J. R., J. Mestecky, C. O. Elson, and H. Kiyono. 1989. Regulation of IgA synthesis and immune response by T cells and interleukins. J. Clin. Immunol. 9:175-199.

18. Ogawa, T A Tarkowski, M. L. McGhee, Z Moldoveanu, J Mestecky, H. Z. Hirsch, W. J. Koopman, S. Hamada, J. R. McGhee, and H. Kiyono. 1989. Analysis of human IgG and IgA subclass antibody-secreting cells from localized chronic inflammatory tissue. J. Immunol. 142:1150-1158.

19. Hirano, T., K. Tasukawa, H. Harada, T. Taga, Y. Watanabe, T. Matsuda, S. Kashiwamura, K. Nakajima, K. Koyama, A. Iwamitsu, et al. 1986. Complementary DNA for a novel human interleukin (BSF-2) that induces B lymphocytes to produce immunoglobulin. Nature (Lond.). 324:73-76.

20. Bjerke, K., P. Brandtzaeg, and T. O. Rognum. 1986. The distribution of immunoglobulin-producing cells is different in normal human appendix and colon mucosa. Gut. 27:667-674.

21. Bockman, D. E. 1983. Functional histology of appendix. Arch. Histol. JPN. 46:271-292.

22. Mestecky, J., and J. R. McGhee. 1987. Immunoglobulin A (IgA): molecular and cellular interactions involved in IgA biosynthesis and immune response. Adv. Immunol. 40:153-245.

23. Benson, E. B., and W. Strober. 1988. Regulation of IgA secretion by T cell clones derived from the human gastrointestinal tract. J. Immunol. 140:18741882.

24. Crago, S. S., W. H. Kutteh, I. Moro, M. R. Allansmith, J. Radl, J. J. Haaijman, and J. Mestecky. 1984. Distribution of IgA 1-, IgA2-, and J chain-containing cells in human tissues. J. Immunol. 132:16-18.

25. Kett, K., P. Brandtzaeg, J. Radl, and J. J. Haaijman. 1986. Different subclass distribution of IgA-producing cells in human lymphoid organs and various secretory tissue. J. Immunol. 136:3631-3635. 